\title{
INFLUÊNCIA DA CALCINAÇÃO SOBRE A REMOÇÃO DE FERRO DA CAULINITA E ILITA E SEUS EFEITOS SOBRE A ACIDEZ
}

Cleber S. de Araújo e Lindomar R. Damasceno da Silva*

Departamento de Química Orgânica e Inorgânica, Universidade Federal do Ceará, Campus do Pici, CP 6002, 60451-970

Fortaleza - CE

Recebido em 15/10/01; aceito em 19/9/02

\begin{abstract}
INFLUENCE OF THE CALCINATIONS IN IRON REMOTION OF KAOLINITE-ILLITE AND THESES EFFECT ON THE ACIDITY. Samples of natural clay composed by kaolinite, illite, goethite and quartz, were calcinated and submitted to lixiviation with citrate and chloridric acid in order to remove iron. Investigation due to extraction consequences was carried cut by analyzing its acid properties using ammonia gas as probe in infrared spectrophotometry analysis. The sample that were treated with citrate followed by acid lixiviation yield materials twice more acid than samples treated with acid only.
\end{abstract}

Keywords: calcination; iron extraction; lixiviation acid; sodium citrate.

\section{INTRODUÇÃO}

Nas últimas décadas as argilas têm sido utilizadas para diversos fins científicos e tecnológicos, tais como: na catálise, nos processos de adsorção, na purificação de óleos vegetais, dentre outros ${ }^{1,2}$. Essas potencialidades são decorrentes das propriedades físico-químicas que as mesmas apresentam, como capacidade de troca de cátions (CTC), natureza dos cátions trocáveis, distribuição granulométrica das partículas, área específica, porosidade, potencial eletrocinético, viscosidade em suspensão aquosa e plasticidade ${ }^{3}$, que podem ser alteradas visando aumentar a sua eficiência ${ }^{4,5}$.

Devido à variedade de combinações dos minerais precursores, tem sido freqüente a presença de certas espécies minerais, que se constitui num problema para as aplicações das argilas, principalmente como catalisadores ou adsorventes. A presença de ferro, por exemplo, que pode ser encontrado em diversas formas minerais (hematita, algita, goetita, hidróxido de ferro(III) amorfo, entre outros), tem sido uma preocupação imediata quando se trata da produção de catalisadores ácidos, tendo em vista que o ferro pode interferir na acidez das argilas. São encontrados na literatura métodos de eliminação dessa espécie ${ }^{6,7}$, bastante eficazes, e que podem contribuir positivamente para o aumento no número de sítios ácidos de Lewis e de Brönsted $^{8}$, indispensáveis aos processos de craqueamento, isomerização, ciclização de compostos orgânicos, entre outros ${ }^{9}$. Tendo em vista esse problema, pretendeu-se investigar a presença do ferro e sua influência sobre as propriedades ácidas de argila sedimentar encontrada no município de Fortim, litoral leste do estado do Ceará.

\section{PARTE EXPERIMENTAL}

Previamente ao estudo sobre a eliminação do ferro e seus efeitos sobre a acidez, foram realizadas algumas análises físicas para caracterização da argila de partida. Foi obtido, inicialmente, um espectro de difração da fração 200 mesh, em um difratômetro modelo Universal X-ray diffractometer D/MAX 3B Rigaku, numa geometria Bragg-Brenteno, CuKa e monocromador de grafite pirolítico curvo. Uma análise posterior, foi a determinação do comportamento térmi-

*e-mail: lindomar@dqoi.ufc.br co das espécies minerais presentes, em um equipamento da PerkinElmer TGA-7, em fluxo de ar e velocidade de aquecimento de $10{ }^{\circ} \mathrm{C} / \mathrm{min}$, e algumas determinações da textura da argila, como área específica e porosidade total em um analisador BET Flowsorb 2300 Micrometric Equipaments. Quanto à determinação dos componentes químicos da argila, foram realizadas análises químicas por via úmida em equipamento de absorção atômica AA12-1475 Gemini.

As etapas de investigação da presença de ferro em amostras da argila de Fortim foram conduzidas como mostrado no fluxograma (Figura 1).

Para a remoção de ferro da argila, utilizou-se o método do citrato ${ }^{7}$, que tem demonstrado ser apropriado às argilas, pois não afeta a estrutura dos argilominerais presentes ${ }^{10}$.

Antes da remoção da goetita, realizou-se uma análise termogravimétrica para verificar o comportamento térmico dos minerais presentes e determinar a água de hidratação, principalmente da goetita, para se ter uma melhor compreensão do seu comportamento na solução coloidal.

Para as lixiviações ácidas e saturação com vapor de amônia, foram utilizadas quatro amostras, sendo duas não calcinadas, denominadas de SFFe210 e SF210, e duas calcinadas, SFFe260 e SF260, conforme fluxograma (Figura 1). Pesou-se $100 \mathrm{mg}$ de cada amostra, transferiu-se para erlenmeyers e adicionou-se $20 \mathrm{~mL}$ de ácido clorídrico, $6 \mathrm{M}$. As suspensões foram mantidas sob agitação à temperatura ambiente, e ao final de $2 \mathrm{~h}$ foram lavadas até $\mathrm{pH}$ neutro, e secas em estufa a $110{ }^{\circ} \mathrm{C}$. As fases aquosas foram utilizadas para análises de ferro. Após saturação com vapor de amônia e diluição em $\mathrm{KBr}$ a $5 \% \mathrm{~m} / \mathrm{m}$, as amostras foram analisadas em espectrofotômetro de infravermelho Perkin-Elmer Espectrum 1000,

\section{RESULTADOS E DISCUSSÃO}

O difratograma da fração argila 200 mesh (Figura 2) revela a presença de quatro espécies minerais, sendo duas delas os argilominerais caulinita e ilita, além do quartzo e da goetita. Este último, de composição química $\alpha-\mathrm{FeOOH}$, apresenta-se agregado aos argilominerais, sendo de difícil remoção por meios físicos ${ }^{6}$.

Através da curva de TG (Figura 3 ) verifica-se uma perda de massa inicial, a $50{ }^{\circ} \mathrm{C}$, decorrente da umidade retida pela argila nas condições de temperatura e pressão em que ela se encontrava no ambi- 


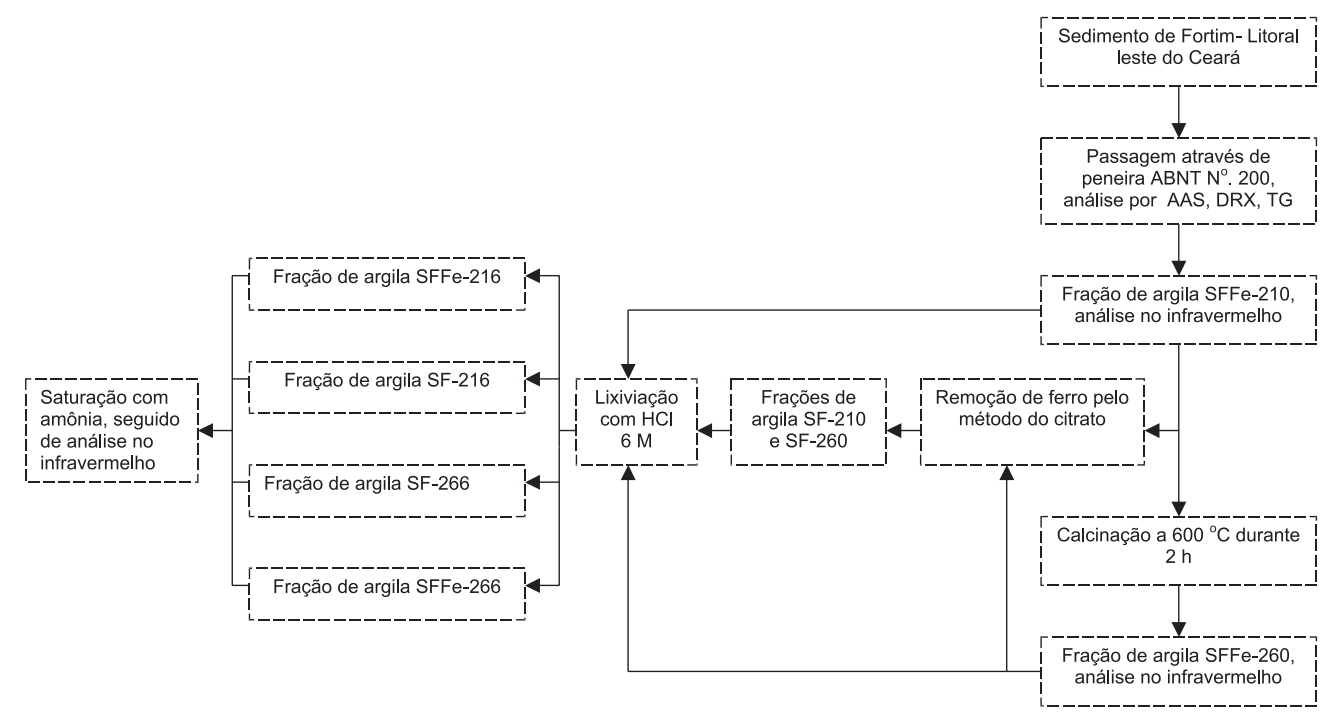

Figura 1. Fluxograma experimental do processo de remoção de ferro com citrato de sódio e lixiviação ácida

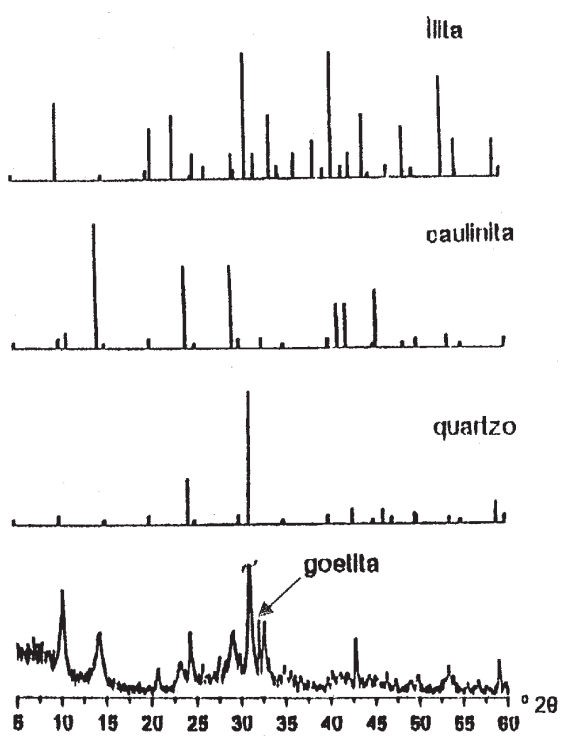

Figura 2. Difratograma de raios- $X$ do sedimento Fortim com granulometria 200 mesh

ente. A partir de $400{ }^{\circ} \mathrm{C}$ inicia-se uma perda de massa progressiva, na qual se identificam duas etapas que ocorrem simultaneamente, sendo que, o evento que se passa a uma temperatura ligeiramente maior, prolonga-se até cerca de $800{ }^{\circ} \mathrm{C}$, e logo a seguir sofre um ganho de massa, o qual é atribuido à formação do $\mathrm{Fe}_{2} \mathrm{O}_{3}$, a partir da goetita. Outra mudança identificada foi a alteração na geometria das folhas de gibsita com mudança no índice de coordenação do alumínio, passando de octaédrico para tetraédrico, em decorrência da perda de hidroxilas, como mostram os espectros de IV (Figura 4). A banda em $912 \mathrm{~cm}^{-1}$, atribuída aos estiramentos Al-OH da estrutura da gibsita, não mais aparece no espectro B da mesma figura, resultado da calcinação a $600{ }^{\circ} \mathrm{C}$. Segundo Gil et al. ${ }^{11}$, esta nova condição favorece uma troca iônica por $\mathrm{H}^{+}$mais efetiva, quando do ataque ácido, levando a uma estrutura com cerca de três vezes mais sítios ácidos do que a estrutura contendo átomos de alumínio octaédricos.

A área superficial específica e a porosidade da fração argila 200 mesh foram, respectivamente, $34 \mathrm{~m}^{2} \cdot \mathrm{g}^{-1}$ e $8 \mathrm{~cm}^{3} \cdot \mathrm{g}^{-1}$. Estes valores

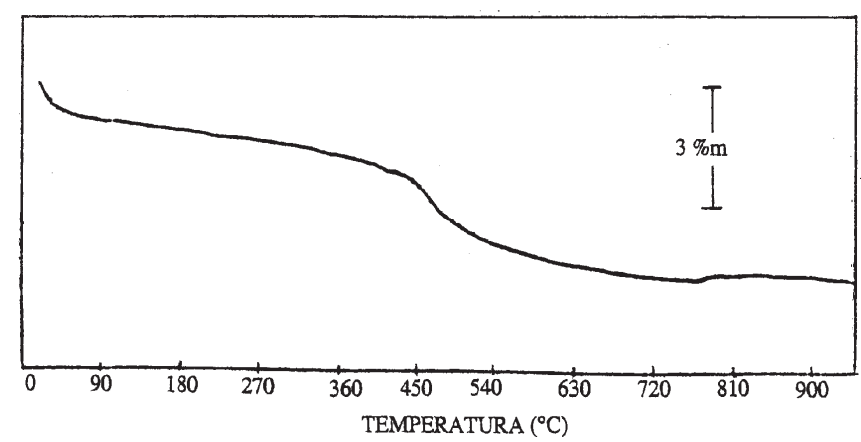

Figura 3. Curva termogravimétrica de amostra do sedimento Fortim com granulometria 200 mesh, sob fluxo de ar e $10^{\circ} \mathrm{C} / \mathrm{min}$

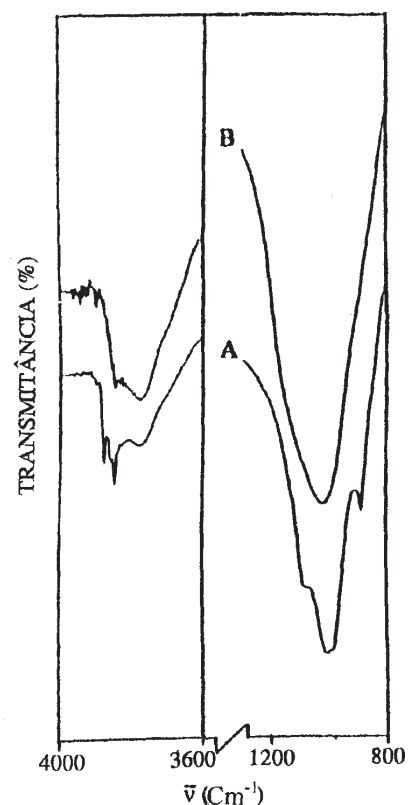

Figura 4. Espectros de absorção no infravermelho de amostras do sedimento Fortim. Antes da calcinação, SFFe210 (A) e após calcinação a $600{ }^{\circ} \mathrm{C}$, SFFe260 (B) 
indicam que a fração argila se encontra finamente dividida, e com alto grau de empilhamento, favorecendo, assim, a dispersão em meio aquoso.

As análises químicas resultaram nos valores apresentados na Tabela 1, na qual se observa elevada quantidade de silício total, decorrente da presença do quartzo. Já a parte de sílicio que é atribuída às estruturas da caulinita e ilita leva a uma relação $\mathrm{Si}$ : $\mathrm{Al}$ um pouco superior à atribuída ao grupo dos argilominerais do tipo $1: 1$, nos quais está inserida a caulinita. Com isso, acredita-se que esta esteja em quantidade superior à ilita, que pertence ao grupo $2: 1^{10}$. Outro valor que chama a atenção é a quantidade da espécie ferro, que tem sido atribuída à presença do mineral goetita.

Após conhecer as características químicas e estruturais da argila, esta foi utilizada como descrito no diagrama da Figura 1. As amostras SFFe210 e SFFe260, após terem sido tratadas com citrato, resultaram nas amostras denominadas SF210 e SF260. As quatro amostras foram então lixiviadas com ácido clorídrico $6 \mathrm{M}$. Como os argilominerais apresentam capacidade de troca iônica espontânea das espécies $\mathrm{Ca}^{2+}, \mathrm{Mg}^{2+}, \mathrm{Na}^{+}$e $\mathrm{K}^{+}$pela espécie $\mathrm{H}^{+}$, tem sido possível obter estruturas com acidez elevada. Quanto à capacidade de troca iônica da caulinita, tem-se encontrado valores que variam de 3 a 15 meq, e para a ilita de 10 a 40 meq para cada 100 g de argila ${ }^{2}$. Segundo Gomes ${ }^{7}$, essas diferenças são decorrentes da quantidade de determinadas espécies trocáveis na estrutura e, quanto maior for a valência e menor a hidratação, tanto maior será a capacidade de troca iônica. Por essa razão, cátions monovalentes obedecem a seguinte ordem de força iônica : $\mathrm{H}^{+}>\mathrm{Cs}^{+}>\mathrm{Rb}^{+}>\mathrm{NH}_{4}^{+}>\mathrm{K}^{+}>\mathrm{Na}^{+}>\mathrm{Li}^{+}$, e a sequiência, $\mathrm{Ba}^{2+}>\mathrm{Sr}^{2+}>\mathrm{Ca}^{2+}>\mathrm{Mg}^{2+}$, para os cátions bivalentes ${ }^{12}$.
Após a lixiviação foram determinadas as quantidades de ferro removido da amostra por complexação, como apresentado na Tabela 1. Observa-se que as quantidades de ferro encontradas nos sobrenadantes das amostras submetidas ao citrato são menores que para as submetidas diretamente à lixiviação ácida. Já o fato da quantidade de ferro removido da amostra SF266 ser bem inferior à dos demais deve-se, presumivelmente, ao fato da goetita estar na forma de óxido, facilitando a remoção, pois como tal, este mineral perde a capacidade de hidratar e com isso, não forma uma solução coloidal ${ }^{11}$.

Para a determinação da variação de acidez na argila, decorrente da saída da goetita e das lixiviações com ácido mineral, as amostras foram saturadas com vapor de amônia, para a visualização da quantidade e da natureza dos sítios ácidos através de espectroscopia na região do infravermelho.

Nos espectros das Figuras 5 e 6 identificam-se os estiramentos correspondentes aos sítios ácidos de Lewis, $1440 \mathrm{~cm}^{-1} \mathrm{e} 3300 \mathrm{~cm}^{-1}$, e os de Brönsted, $1620 \mathrm{~cm}^{-1}$ e $3100 \mathrm{~cm}^{-1}$. O espectro D referente à amostra $\mathrm{SFFe} 216-\mathrm{NH}_{3}$, que não teve o ferro removido, indica um certo grau de acidez de Lewis, pois há o aparecimento de uma banda em $1410 \mathrm{~cm}^{-1}$, que comparada com a amostra SF216- $\mathrm{NH}_{3}$, verificase uma diminuição da intensidade da banda, indicando uma redução na incidência de sítios ácidos de Lewis. Com isso, fica evidente que a presença de ferro na amostra tende a impedir o aparecimento de sítios ácidos de Lewis. Observando a região de alta freqüência do espectro, $3000 \mathrm{~cm}^{-1}$ a $4000 \mathrm{~cm}^{-1}$, o mesmo fenômeno é notado. A partir do desdobramento das bandas e cálculo das suas respectivas áreas, estimou-se que a acidez de Lewis na amostra sem ferro é duas vezes maior.

Tabela 1. Propriedades físico-químicas da argila de Fortim(200 mesh) e das formas modificadas com citrato de sódio e ácido cloridríco

\begin{tabular}{|c|c|c|c|c|c|c|c|c|c|c|}
\hline \multirow[b]{2}{*}{$\begin{array}{c}\mathrm{SiO}_{2} \text { total } \\
103,4\end{array}$} & \multirow[b]{2}{*}{$\begin{array}{l}\mathrm{SiO}_{2} \\
92,3 \\
\end{array}$} & \multicolumn{3}{|c|}{ Análise Química (ppm) } & \multirow[b]{2}{*}{$\begin{array}{c}\mathrm{MgO} \\
5,6\end{array}$} & \multirow[b]{2}{*}{$\begin{array}{l}\mathrm{MnO} \\
\text { traços }\end{array}$} & \multirow{2}{*}{$\begin{array}{c}\text { SAL } \\
\text { Si:Al } \\
1,18\end{array}$} & \multirow{2}{*}{$\begin{array}{c}\text { Acidez Livre } \\
\text { mEq/100g } \\
\text { de argila } \\
\mathrm{H}^{+}+\mathrm{Al}^{3+} \\
6,6\end{array}$} & \multicolumn{2}{|c|}{$\begin{array}{c}\text { Matéria Orgânica } \\
(\mathrm{ppm})\end{array}$} \\
\hline & & $\begin{array}{c}\mathrm{Al}_{2} \mathrm{O}_{3} \\
74,8\end{array}$ & $\begin{array}{c}\text { Fe total } \\
19,1\end{array}$ & $\begin{array}{c}\mathrm{CaO} \\
5,2\end{array}$ & & & & & $\begin{array}{c}\mathrm{C} \\
0,67\end{array}$ & $\begin{array}{l}\text { Total } \\
1,15\end{array}$ \\
\hline \multicolumn{2}{|c|}{ Amostras } & \multicolumn{3}{|c|}{ SFFe216 } & \multicolumn{2}{|c|}{ SF216 } & \multicolumn{2}{|c|}{ SF266 } & \multicolumn{2}{|c|}{ SFFe266 } \\
\hline \multicolumn{2}{|c|}{$[\mathrm{Fe}] / \mathrm{ppm}$} & \multicolumn{3}{|c|}{4,99} & \multicolumn{2}{|c|}{3,02} & \multicolumn{2}{|c|}{1,62} & \multicolumn{2}{|c|}{4,56} \\
\hline
\end{tabular}

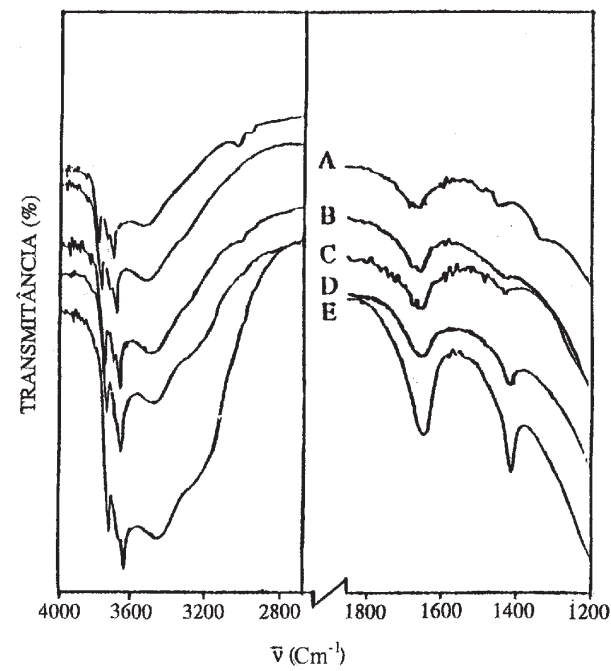

Figura 5. Espectros de absorção no infravermelho de amostra do sedimento Fortim não calcinadas. SFFe210 (A); SFFe216 (B); SF216 (C); SFFe216$\mathrm{NH}_{3}(\mathrm{D}) ; \mathrm{SF} 216-\mathrm{NH}_{3}(\mathrm{E})$

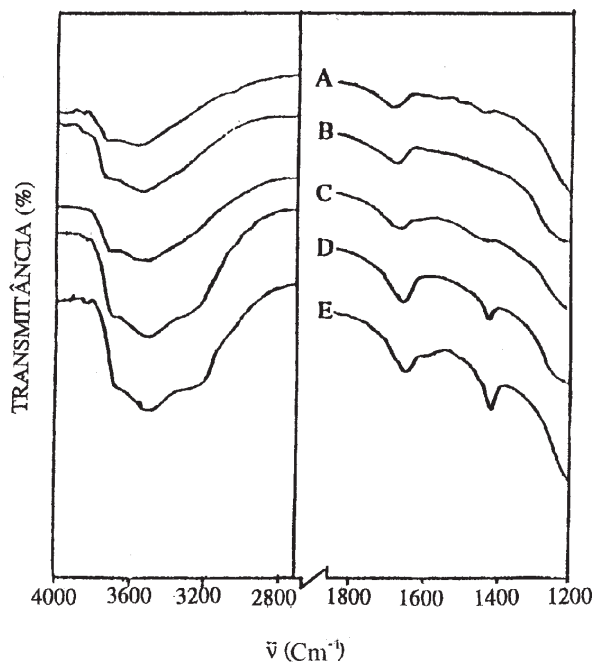

Figura 6. Espectros de absorção no infravermelho de amostra do sedimento Fortim não calcinadas. SFFe260 (A); SFFe266 (B); SF266 (C); SFFe266$\mathrm{NH}_{3}(\mathrm{D}) ; \mathrm{SF}^{266-\mathrm{NH}_{3}}(\mathrm{E})$ 
Tratamento semelhante para as amostras submetidas à calcinação a $600{ }^{\circ} \mathrm{C}$ indica que para a amostra SFFe266 saturada com amônia, a acidez foi o dobro da amostra SFFe216. Com isso, verifica-se que a calcinação favorece o incremento da acidez, indicando que esta é uma prática desejável na preparação de materiais com elevada acidez ${ }^{13}$. A amostra SF266, submetida ao citrato, apresentou acidez comparável com a amostra SF216.

\section{CONCLUSÃO}

As análises espectroscópicas no infravermelho utilizando amônia como sonda molecular mostraram que a presença do ferro inibe o aparecimento de sítios de Lewis. No caso da amostra calcinada, não submetida ao citrato, a lixiviação ácida levou a um incremento de $100 \%$ na acidez, em relação à não calcinada. Já as amostras tratadas com citrato, calcinada e não calcinada, tiveram acidez equivalente entre si, e menores que as anteriores. Para as amostras sem ferro a acidez independe da calcinação.

\section{AGRADECIMENTOS}

Os autores agradecem o apoio da Funcap e Universidade Federal do Ceará, pelo financiamento desta pesquisa, e ao Programa Es- pecial de Treinamento (PET) da Capes pela bolsa do aluno C. S. de Araújo. Agradecem também, aos Profs. Drs. S. Gouveia e J. M. Sasaki pelas análises de ferro por absorção atômica e difração de raios-X, respectivamente.

\section{REFERÊNCIAS}

1. Foletto, E. L.; Volzone, C.; Morgado, A. F.; Mater. Res. 2001, 4, 211.

2. Santos, P. S.; Ciência e Tecnologia das Argilas, 2a. ed., Edgard BlucherEdusp: São Paulo, 1989, vols. 1 e 3.

3. Caillete, S.; Henin, S.; Rautereau, M.; Minerogie des Argiles - Structure et Proprietes Physico-Chimiques, INRA: Paris, 1987, vol. 8

4. Silva, L. R. D. da; Garla, L. C.; Quim. Nova 1999, 22, 169.

5. Mergulies, 1.; Rosen, H.; Nir, S.; Clays Clay Miner. 1988, 36, 270.

6. Ambikadevi, V. R.; Lalithambika, M.; Appl. Clay Sci. 2000, 16, 133.

7. Gomes, C. F.; Argilas, o que são e para que servem, Fundação Calouste Gulbenkian: Lisboa, 1988.

8. Benesi, H. A.; Winquist, B. H. C.; Advances in Catalysis 1978, 27, 97.

9. Theochoris, C. R.; Jacob, J. K.; Gray, A.; J. Chem. Soc., Faraday Trans. 1 1988, 84, 1509.

10. Brindley, G. W.; Brown, G.; Crystal Structures of Clay Minerals and Their X-Ray Identification, Mineralogical Society: London, 1984.

11. Gil, A.; Gandía, L. M.; Vicente, M. A.; Catal. Rev. Sci. Eng. 2000, 42, 145.

12. Turner, R. C.; Brydon, J. E.; Soil Sci. 1967, 103, 111.

13. Gondim, A. C. S.; Silva, L. R. D. da; An. Assoc. Bras. Quím. 1997, 46, 263. 